crisis took place-ice cradling was maintained, with the result that the bed temperature fluctuated between $74^{\circ}$ and $65^{\circ} \mathrm{F}$.; and at the end of that time, the cradling having been discontinued, the thermometer under the blankets registered $87^{\circ} \mathrm{F}$

In this case the effect of the treatment on the body heat was not at all evident. On the afternoons of three successive days the thermometer rose to over $105^{\circ} \mathrm{F}$., elevating the cradle temperature along with it ; but it tinally fell rapidly on the eighth day of the disease to the normal figure. With regard to the pulse and respiration rate, the influence of the ice seemed more apparent, for with temperatures of $105^{\circ} \mathrm{F}$ the pulse was only 100 , and the respirations ranged between 30 and 35 a minute.

On looking over the records of these cases-I refer to the whole of them-I confess I am unable to discover any marked signs of improvement following the complete establishment of the treatment. There was no sudden fall of temperature such as one meets with after the cold bath or after the administration of an antipyretic drug. But though there was no decided reduction in the temperature, the pyrexia (even in one case where both lungs were extensively involved) did not attain a great height, and I am therefore inclined to consider that the treatment exercised a restraining influence on the body heat. The pulse and respirations also seemed to be under restraint, for the heart's action was in no case unduly rapid or weak, and the breathing was never a source of anxiety.

The patients as a rule expressed themselves as feeling comfortable under the treatment. One or two of them, however, complained of cold feet, and in these cases short stockings were permitted to be worn. In one patient inordinate perspiration was a marked feature, but the discomfort arising from this symptom at once disappeared with the establishment of the ice cradling. In the earlier cases some inconvenience was experienced from the accumulation of moisture on the outside of the pails dropping on the patients' body and bed, but this was easily remedied by clothing the pails in flannel.

With regard to the means by which the antipyretic results were brought about, it seems to me that a study of the chart shows in a very decided manner that a twofold influence was at work-the influence of the air under the cradles, and the influence of the ice pails. The temperature under the blankets was materially reduced after simple cradling had been established, and the thermometer became still further lowered on the introduction of the ice pails. It is doubtful which of the factors was the more powerful. I incline to the belief that the lowering of the temperature produced by the cradles was greater than that following the melting of the ice, but possibly this opinion may be modified by future experience, for $I$ intend in my next case of pneumonia to make more careful observations on this point, using pails of different capacities and varying their number.

On the whole, though I am fully alive to the fallacies that attend conclusions based on a small number of cases, I am disposed, from what I have seen of the proceeding, to recommend ice cradling as a mild form of antipyretic treatment, suitable for sthenic cases of acute pneumonia, easy of application, not violent in its effects, comfortable and not fatiguing to the patient, and capable of being carried out in any disease where a restraining influence on pyrexia and its attendant symptoms is desired.

\section{SUPPRESSION OF URINE IN DIPHTHERIA.}

Br LEONARD WILDE, M.D., M.R.C.P., D.P.H. Physician to the Croydon Borough Hospital.

SUPPRESSION of urine occurring in the course of diphtheria has been described by Oertel and mentioned by Roberts. Hilton Fagge believed it to be due to unrecognised scarlet fever. As, however, it has recently been attributed to the effects of antitoxin, the following 3 cases, which were admitted into the Croydon Borough Hospital for Infectious Diseases during the past twelve months, and in which this exceptional complication occurred without any antecedent injection of antitoxin, may be of interest.
Cases $\mathrm{I}$ and II were admitted before antitoxin was in general use in this country, and Case IIr, although clinically indistinguishable from true diphtheria, was not bacterioscopicalls confirmed, and the patient therefore was not injected.

For the notes of the cases I am indebted to Mr. A. Kidd, resident medical officer.

CASE I. Pharyngeal and Nasal. Diphtheria: Suppression of Urine during the Second Week of Illness.-A girl, A.H., aged 4, was admitted on June 20th, 1894. There was a history of two days' antecedent sore throat. The tonsils were ragged and inflamed, and covered with a grey pultaceous exudation. There was a fotid nasal discharge, and considerable swelling of the upper cervical glands. The temperature was $101.6^{\circ}$, the pulse 126 and regular; the respirations were 26 , and air was entering both lungs freely. The urine was normal. On June 22nd the child was very pale, and extension of membrane had occurred over the soft palate and uvula. Several large pieces came away from the throat and nose. The temperature continued about $101^{\circ}$. On June 24th paralysis of the soft palate was observed, and the knee-jerks and plantar reflexes were absent. Vomiting and diarrhoea, accompanied by a diminution of urine and the presence of albumen were noted. During the following three days intractable diarrhœa and vomiting continued, the urine progressively decreased, and the child was very anæmic, apathetic, and weak. On June 28th the temperature dropped to $96.4^{\circ}$, and total suppression of urine supervened, which continued until death occurred on June 29 th, thirty-six hours after the onset of anuria.

CASE II. Pharyngeal and Nasal Diphtheria: Suppression of Urine on the Sirth Day of the Disease.-N. B., a girl aged 3, was admitted on September 27th, 1894, with a history of indefinite illness for the previous three days. On admission, the child was pale and appeared to have considerable difficulty in breathing, though air was freely entering both lungs. The tonsils were enlarged and covered with thick yellow exudation. There was profuse fotid nasal discharge and foul breath. The glands at the angle of the jaw were enlarged. The temperature was $100.2^{\circ} \mathrm{F}$. and the pulse 132 . The urine was normal in quantity but contained a trace of albumen. The knee-jerks were absent. On the following day some shreds of membrane were coughed up; the condition of the throat remained the same and paralysis of the soft. palate appeared. On September 29 th recurrent vomiting and diminution in the quantity of urine were noted. On September 30th, no urine having been passed since the previous day, a catheter was introduced and 3 ounces of urine containing oneeighth albumen withdrawn. The bowels were constipated but acted freely after enemata. Vomiting continued. The temperature was $99.6^{\circ}$. The child was very languid and anæmic. Death occurred on October 1st, there having been complete anuria for thirty-six hours prior to death.

CASE III. Pharyngeal and Nasal Diphtheria: Suppression of Urine on the Fourteenth Day of Illness.-J. P., a girl, aged 4 was admitted on April 3rd, 1895. She had been feverish, and complained of headache since March 30th. Sore throat and swelling of the neck were noticed on April 2nd. On admission the tonsils were swollen, and covered with grey membrane, and the upper cervical glands were much enlarged. The temperature was $103^{\circ} \mathrm{F}$., the pulse was 132 , the respirations 24. The chest was clear and the urine normal. On April 5th there was some extension of membrane on the right side, the tongue was dirty, and slight epistaxis occurred. The kneejerk was absent on the left side. The face was of good colour, the temperature $101^{\circ} \mathrm{F}$. On April 6th an offensive nasal discharge appeared, and both tonsils and the soft palate were covered with false membrane. The urine showed a trace of albumen on April 8th. She looked pale, and vomiting and diarrhœa commenced; shreds of membrane came away from the nose. During the following four days there was some improvement in the condition of the throat and less fœetor. The quantity of albumen increased to onefifth, and the vomiting was intermittent. The child was anæmic and languid. On A pril 12th and 13th the improvement in the throat and nose continued, but the vomiting and diarrhoa were almost continuous. The heart's action was occasionally irregular, and the child was somewhat drowsy. The temperature was normal. The urine had decreased in quantity, and contained only a trace of albumen. On April 14th total sup- 
pression of urine had existed since the previous night. Copious watery vomiting and diarrhœa continued. The pulse was 98 , and of low tension. The child became semiconscious and died in convulsions after a period of thirty-one hours of complete anuria.

Post mortem, the tonsils and pharynx were ragged, injected, and exhibited a few scattered patches of pellicular débris. The trachea, bronchi, and lungs were healthy. The heart substance was paler than normal, and the right auricle and ventricle were filled with a buff-coloured ante-mortem clot adherent to the cardiac walls, and extending into the pulmonary artery. Great hyperæmia of the walls of the intestines was observed, and the mucous membrane of the stomach and intestines showed a uniform injection. The macroscopic appearances of the kidneys and other organs were healthy.

REMARKS.-Few deductions can of course be made from such a small series of cases, but it will be observed that certain features were present in all three. The type of the disease was very severe, and there was evidence of a general systemic infection against which the most active treatment was of no avail. The nasal cavity was implicated in each case, and pallor, languor, and debility, with the physical signs of peripheral paralysis, were prominent. In two of the cases the supervention of anuria occurred in the afebrile period of the illness, and it was accompanied by profuse diarrhœa and vomiting. It was of gradual onset, and the urine obtained before total suppression contained a considerable quantity of albumen without casts. The heart was not particularly affected.

The marked selective incidence of the diphtheria virus on peripheral nerve tissue, and the fact that a local diminution of the renal blood pressure leading to suppression may be produced by paralysis due to nervous injury, suggest that the cause of the anuria in these cases may possibly be the result of nerve degeneration. Moreover, the frequent association of an intractable and copious vomiting and diarrhœa might indicate a profound interference with the functions of the abdominal sympathetic system, leading to the blood-flooding of the splanchnic area and the consequent lowering of the renal blood pressure to the point at which urinary filtration can no longer occur.

\section{THE TRUSTWORTHINESS OF THE PRESENT-DAY PREPARATIONS OF THE DIGESTIVE FERMENTS.}

BY EDMUND MOODY SMITH, M.D.EDIN., D.P.H.CantaB. York.

Mr recent study in this direction was suggested by the following considerations:

1. No such research is recorded, that I know of, for ten years past, with the exception of the constant tests to which many manufacturers put their products before sending them into the market.

2. Some of the older preparations which successfully "passed" the tests of such observers as Dowdeswell, Tuson, and Sir William Roberts still exist and maintain their reputation. But many other preparations were proved to be so feeble, that not only did they cease to exist apparently. but their uselessness cast disrepute upon all pepsin and allied digestive preparations alike, upon the good as well as upon the bad and indifferent.

3. There are now an immense number of new preparations of various forms, and by many different makers, advertised and in other ways constantly brought under our notice. The question again arises. Are all these numerous, and in some cases very pretentious, preparations trustworthy and well prepared? Are they equal to requisite and recomised standards? It is most satisfactory to find that the observations of ten and fifteen years ago have been followed by most marked improvements in the quality, purity, and power of these invaluable digestive aids, not one of the greatly advertised preparations failing to realise the British Pharmacopoia's requirements.

I have made a large number of experimental observations,

1 An abstract of "Commended" Thesis for degree of M.D.Edin. most of them being of short but sufficient character, and with the simplest possible apparatus. It is obvious that however elaborate the experimental apparatus devised, we cannot by any means exactly and completely imitate the natural, steadily and continuously maintained processes of normal digestion, the factor of epithelial activity alone being quite beyond our imitation. Again, it is most probable, if not a proven fact, that the glands keep up a constant outpouring of their secretion during the digestive processes with which they are concerned. This is another factor very difficult to take into consideration in exact experiments. Clinical observation supports the wisdom of Fairchild's recommendation that prepared pepsins are best taken in small doses, repeated several times between each meal, instead of being taken in one full dose just before, with, or soon after a meal; and in actual practice this method often answers better than the one full dose method, which to many practitioners must have not infrequently proved perplexingly disappointing.

In my very humble research I was obliged to limit myself to the well advertised preparations, it being far too great a task to test those of every manufacturer, however excellent they may be; and in dealing with the pepsins my experiments were almost wholly carried out according to the British Pharmacopaia test, the United States Pharmacopceia test being far too long and elaborate for use by a general practitioner, liable as he is to numerous interruptions at most inconvenient times. I venture to claim that to the clinical workman, however, the results are none the less serviceable, and as they have already proved so to my own immediate circle of medical friends, this abstract is contributed in the hope that they may be found equally so to a still larger circle of colleagues.

In testing the pepsins I have not attempted to go far towards verifying the extraordinary powers to which some of them lay claim, although, with nearly all, such capacities were realised far exceeding the standard demands. Indeed, these great powers are only to be realised by experiments, each of several hours' duration.

In every case repeated experiments were performed before the trustworthiness of the subject of experiment was admitted, and with the pepsins tinely-minced cooked mutton and beef were digested as well as egg albumen. Mere solution of the albumen was not relied upon as the sole test, but, where digestion was progressing but slowly I made use of one of the most trustworthy of the tests for peptones, which is carried out as follows: Having neutralised the hydrochloric acid with liquor potassæ, a drop or two of Fehling's solutiontest for glucose-is added : if peptones be present in any quantity, however little, a delicate rose-pink coloration is produced, which is of deeper tint according to the amount of peptone present.

The amount of peptone can be accurately calculated by this test, but after a little experience of its use, one also becomes familiar with the various degrees of tint obtained, and can form some approximate idea of the relative activity of the pepsin under experiment. Preparations of pepsin vary-largely according to their mode of preparation, I think, -in the length of time required to effect solution of an equal quantity of boiled egg albumen. For the latter, however finely divided it may be, swells up considerably in the acidulated water (diluted hydrochloric acid), and therefore the peptic solution of it is obscured for a time, until. indeed, some considerable portion has been dissolved. It is obviously unfair, then, altogether to condemn a pepsin as useless if within the given limited time of the British Pharmacopcia test, it fails to effect complete solution of the stipulated amount of albumen. (This was the way by which some pepsins were altogether condemned in the course of some past researches of this character.) Hence the importance of employing the peptone tests in every experiment which appears at all doubtful in its progress or result. More than once I found progressive peptic digestion to be going on, but so deceptively slow that it was almost impossible to recog. nise it from the mere appearance of the albumen undissolved.

The same necessity for not trusting entirely to negative tests nor to mere appearances was equally marked in my experiments with regard to the digestion of starch by the 